\title{
Los tres pasos de la catequesis eucarística de San Agustín a los neófitos
}

La teología eucarística agustiniana se ha visto a menudo lastrada por diversos problemas. Uno de ellos, la duda de si el santo admitió realmente o no la presencia real de Cristo bajo las especies del pan y vino, según la terminología posterior. Y no estamos ante agua pasada, sino ante agua que sigue fluyendo aún en el presente.

En el 2004 se publicó en Italia un Manual de teología sacramentaria especial, dedicado a los sacramentos del Bautismo, Confirmación y Eucaristía ${ }^{1}$. Este último sacramento está confiado a C. Rocchetta. En su recorrido por la historia del Dogma, llega a los Padres latinos y, como uno de ellos, a san Agustín. Comienza presentando su doctrina eucarística como más compleja que la de san Ambrosio, cosa que no se discute. Luego afirma que se mueve entre el realismo y el simbolismo. Por un lado -escribe-, en cuanto obispo, da pruebas de fidelidad a la convicción de la Iglesia sobre la presencia real de Cristo en la Eucaristía, declarando que el pan puesto sobre el altar y el contenido del cáliz, consagrados por la fuerza de la palabra de Dios, constituyen el cuerpo y sangre del Señor 2 ; por otro, en cuanto teólogo, se esfuerza por interpretar el misterio, introduciendo aportaciones personales en las que no falta algún elemento de debilitamiento de la doctrina eucarística. El autor cree que el problema de fondo radica en el concepto de signo pues, según san Agustín, el signo (signum) remite a la realidad (res), pero no se identifica con ella: El signo es algo distinto respecto de la realidad por él significada ${ }^{3}$. La correspondencia entre el signum y la res significada -sigue diciendo-se funda sobre una re-

1. Florio, M., - RocchetTA, C., Sacramentaria Speciale I. Battesimo, confermazione, eucaristia (Corso di teologia sistematica 8a), Edizioni Dehoniane, Bologna 2004.

2. Referencias a s. $227 ; 234,2 ; 272 ;$ en. Ps. 98,$9 ; 33,1,10 ;$ ciu. 10,20 .

3. Referencias a s. 57,$7 ; 71,11,17 ; 112,4 ;$ Io. eu. tr. 25,12; 27,2.3.5; ciu. 21,20.25; en. Ps. 98,9. 
lación de semejanza, no de identidad efectiva. En consecuencia, sólo secundum quemdam modum el sacramento del cuerpo de Cristo es el cuerpo de Cristo, y el sacramento de la sangre de Cristo es la sangre de Cristo 4 . La realidad objetiva (res) del cuerpo y de la sangre del resucitado no está contenida en forma física en los signos consagrados, sino en la misma manera como el signo contiene la realidad y remite a ella: Aliud uidetur, aliud intelligitur ${ }^{5}$. De aquí la distinción modal entre el cuerpo histórico de Jesús y el cuerpo sacramental presente sobre el altar: la cena es un signo (signum) del cuerpo y de la sangre asumidos por Jesús en la encarnación y en forma de la cual se ha ofrecido en la cruz, pero no es la misma res del cuerpo y sangre de Cristo. Una concepción que permite a Agustín enseñar cómo los malos, los herejes y los católicos indignos reciben los dones consagrados en el signo, pero no en la realidad; los reciben como signum, pero no como res ipsa ${ }^{6}$. Y concluye: «No se puede negar que la interpretación del doctor de Hipona se desarrolla según un estatuto fuertemente simbólico y suscite algún interrogante sobre el sentido de la presencia real de Cristo en la Eucaristía». También aduce las causas: «Los motivos de tal planteamiento se derivan ya de un presupuesto medio-platónico que tiende a infravalorar lo visible respecto de lo invisible, ya de una cristología que no logra tener la debida cuenta del realismo de la encarnación, ya, sobre todo, de una eclesiología que no quiere admitir el otorgamiento de la gracia -y, por tanto, también del cuerpo y sangre de Cristo- a quienes, por cisma o herejía, están fuera de la Iglesia». Luego añade: «El aspecto débil de la interpretación agustiniana resulta compensado por el hecho de que, en ella, la res eucharistiae a la que remite el signum no es sólo el cuerpo individual de Cristo, sino también al mismo tiempo, el eclesial, el Christus totalis (sic), caput et corpus, es decir, el Cristo glorioso que asimila a sí la unidad de los cristianos que viven en él por el Bautismo y los hace su signo real in re ipsa». Tal es la presentación que hace C. Rocchetta de la teología eucarística del obispo de Hipona7.

En esta presentación no todo lo afirmado es fácil de aceptar. Considerando la persona, resulta difícil de asumir esa especie de «split theory» que se le supone: confesar como obispo una realidad que luego rechaza, en mayor o menor grado, como teólogo. Si una descoordinación de esas características es difícil de aceptar en cualquier sujeto normal, lo es mucho más en alguien como san Agustín. No cabe pensar que no la advirtiera, en el caso de producirse, dada su elevada capacidad intelectual reconocida

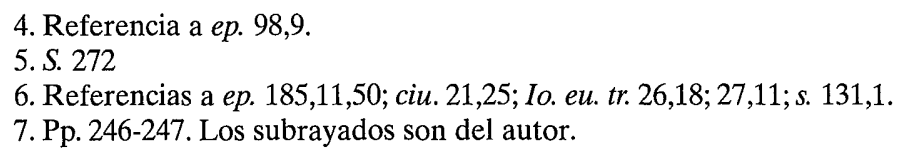


por todos; $\mathrm{y}$, dado su absoluto respeto por la verdad, tampoco cabe admitir que, de forma consciente, jugase con alternativas de las que sabía que, una al menos, tenía que ser falsa. Y tanto menos tratándose de un punto central de la fe de la Iglesia en la que ejercía el ministerio de pastor, la Católica. A nivel doctrinal, algunos de los argumentos aducidos nos parece que carecen realmente de peso. Entre ellos el que se apoya en la frase aliud uidetur, aliud intellegitur con que el santo describe la realidad sacramental. En las páginas que siguen trataremos de descubrir su significado y sentido, leyéndola en su contexto. Por ello, analizar la frase conlleva analizar también todo el sermón 272 que la contiene. A su vez, el examen de este sermón reclama el examen de otros tres asimilables a él: el 227, el 229 y el $229 \mathrm{~A}$. El análisis revela que el obispo Agustín procede de modo similar en todos ellos.

Que el predicador proceda de modo similar en los cuatro sermones es comprensible, considerados los aspectos que tienen en común. Todos fueron predicados en la misma circunstancia; todos constituyen una catequesis sobre la Eucaristía, tenida en la mañana del domingo de Pascua, a los neófitos que, en la noche anterior, durante la Vigilia Pascual ${ }^{8}$, habían recibido los tres sacramentos de la iniciación cristiana ya mencionados: el Bautismo, la Confirmación y la Eucaristía. Añadamos que no se trata de una catequesis más, sino de la primera que los nuevos fieles recibían sobre este último sacramento, recibido pocas horas antes. El momento era solemne; sin duda, el más solemne y el más gozoso del año en la vida de la Iglesia, que veía cómo, Pascua tras Pascua, se acrecentaba el número de sus hijos con nuevos nacimientos. Todo nacimiento es vida y toda vida es motivo de gozo. Celebraba, sí, la Pascua del Señor, pero también la Pascua de esos nuevos iniciados en la fe y vida de la Católica.

\section{Tres pasos de la catequesis eucarística}

Veamos de cerca ese modo de proceder, analizando los cuatro sermones mencionados.

a) Sermón $272^{9}$. Este sermón, de naturaleza catequética como acabamos de indicar, es, por su contenido, uno de los textos clave de la teología

8. Aunque cabe que el s. 272 haya sido predicado en semejante contexto, pero en la Vigilia de Pentecostés. Cf. nota siguiente.

9. Todos los autores coinciden en colocarlo entre el año 405 y el 411 , aunque unos creen que fue predicado el día de Pascua, otros que en la vigilia de Pentecostés o el día mismo de Pentecostés. 
eucarística agustiniana y, desde el punto de vista de la metodología teológico-eucarística, el texto clave para conocerla. El iter mental que, sin mencionarlo, sigue el santo en otros sermones eucarísticos, en este lo presenta de forma explícita.

El predicador comienza con estas palabras: «Lo que veis puesto sobre el altar de Dios, lo visteis también la noche pasada, pero aún no habéis oído qué es, qué significa, de cuán gran realidad es signo». Tenemos, pues, señalado un iter que consta de tres pasos: advertir algo, saber qué es, conocer qué significa, (esto es,) de qué realidad es signo ${ }^{10}$. Estos tres pasos son explicitados a continuación: $1^{\circ}$ ) «Lo que estáis viendo es el pan y el cáliz, que vuestros mismos ojos os hacen ver». $2^{\circ}$ ) «En cambio, según la fe en que tenéis que estar instruidos, el pan es el cuerpo de Cristo, el cáliz es la sangre de Cristo». $3^{\circ}$ ) «Esto, dicho así brevemente, quizá baste a vuestra fe. Pero la fe reclama ser instruida. Dice, en efecto, el profeta: Si no creéis, no entenderéis (Is 7,9 [LXX])» ${ }^{11}$. Estos tres pasos se pueden caracterizar, pues, por tres verbos: el ver, el creer, el entender. Significativamente, el desarrollo posterior del sermón se ocupa casi exclusivamente del tercer paso; de hecho, cuando hable del pan y del vino, elementos del primero, será en función del tercero.

En este sermón el primer paso es breve; se limita a constatar la presencia sobre el altar del pan y del vino, perceptible a los ojos. El segundo paso afirma de forma clara y rotunda la presencia real del cuerpo y sangre de Cristo en la Eucaristía. La respuesta a la pregunta sobre qué es lo que se ve sobre el altar es inapelable: «El pan es el cuerpo de Cristo; el cáliz ${ }^{12}$ es la sangre de Cristo». Pero es también breve en su formulación. El tercer paso, además de llenar buena parte del sermón, tiene un prólogo justificativo. Esta justificación comienza ya en el segundo -«la fe en la que tenéis que estar instruidos»- y aparece reafirmada a continuación al indicar que la fe reclama instrucción (instructionem desiderat), esto es, inteligencia. En este contexto recurre a Is 7,9, según los LXX: 'Si no creéis, no entenderéis (non intellegetis)'. Incluso pone en boca de sus oyentes

10. Interpretamos esta última frase como aposición explicativa de la anterior.

11. S. 272: «Hoc quod uidetis in altari dei, etiam transacta nocte uidistis: sed quid esset, quid sibi uellet, quam magnae rei sacramentum contineret, nondum audistis. Quod ergo uidetis, panis est et calix; quod uobis etiam oculi uestri renuntiant: quod autem fides uestra postulat instruenda, panis est corpus Christi, calix sanguis Christi. Breuiter quidem hoc dictum est, quod fidei forte sufficiat: sed fides instructionem desiderat. Dicit enim propheta: nisi credideritis, non intellegetis (Is 7,9 [LXX])».

12. Es obvio que san Agustín aquí recurre a la sinécdoque, expresando el contenido, el vino, por medio del continente, el cáliz. 
estas palabras: «nos has mandado que creamos (praecepisti ut credamus), expónnoslo para que entendamos (ut intellegamus)». Acto seguido, el catequista hace un recorrido por las diversas etapas de la vida terrena de Jesús, desde el nacimiento de María hasta su ascensión al cielo, y acaba con la pregunta que supone se hacen los oyentes: si está en el cielo, ¿cómo entonces el pan es su cuerpo y el vino su sangre? Para solucionar la dificultad el santo indica que nos encontramos ante realidades sacramentales (sacramenta) en las que se ve (o parece ${ }^{13}$ ) una cosa, pero se entiende otra (aliquid uidetur, aliquid intellegitur), donde el ver se refiere al aspecto corporal (speciem... corporalem) y lo que se entiende, al fruto espiritual (fructum... spiritualem $)^{14}$. Hablando con propiedad él no responde a la dificultad planteada, que se refiere al segundo paso; fiel a su programa, expone qué se debe entender, esto es, el tercer paso. Del texto no se debe concluir, pues, que el predicador acepte la idea que subyace a la objeción: Si Cristo ascendió al cielo y se mantiene allí, no puede estar sobre el altar bajo los sacramentos del pan y el vino y, por tanto, no se da la presencia real.

El santo ha mencionado los sacramentos. Adviértase, sin embargo, que él no emplea el término con sentido abstracto, sino muy concreto: en el contexto los sacramentos son tanto el pan como el vino consagrados. En primer lugar, san Agustín está dando respuesta a los oyentes que le piden que les exponga (expone) lo que les manda creer para que puedan entenderlo; ahora bien, lo que han de creer es que el pan y el vino son ya el cuerpo y la sangre de Cristo. En segundo lugar, porque sólo estos, el cuerpo y la sangre de Cristo, pueden producir un fruto espiritual. Para enten-

13. La forma uidetur de la frase agustiniana puede pertenecer al verbo transitivo uideo (ver) en pasiva, o al deponente uideor (parecer). Puede que los dos verbos expresan lo mismo desde diversas perspectivas; el primero desde la perspectiva del sujeto cognoscente (es vista, se ve); el segundo, desde la perspectiva del objeto en sí mismo (parece). Hemos elegido la primera opción por mantener la paridad con el segundo verbo (intelligitur). Pero damos por hecho que, en la mente del predicador, el uidetur incluya el significado de ambos verbos: lo que es visto por el fiel cristiano es sólo una apariencia. La realidad objetiva la constituye lo que el fiel cree.

14. S. 272: «Potestis enim modo dicere mihi: praecepisti ut credamus, expone ut intellegamus. Potest enim in animo cuiusquam cogitatio talis suboriri: dominus noster Iesus Christus, nouimus unde acceperit carnem; de uirgine Maria. Infans lactatus est, nutritus est, creuit, ad iuuenilem aetatem perductus est, a Iudaeis persecutionem passus est, ligno suspensus est, in ligno interfectus est, de ligno depositus est, sepultus est, tertia die resurrexit, quo die uoluit, in caelum ascendit; illuc leuauit corpus suum; inde est uenturus ut iudicet uiuos et mortuos; ibi est modo sedens ad dexteram patris: quomodo est panis corpus eius? Et calix, uel quod habet calix, quomodo est sanguis eius? Ista, fratres, ideo dicuntur sacramenta, quia in eis aliud uidetur, aliud intellegitur. Quod uidetur, speciem habet corporalem, quod intellegitur, fructum habet spiritualem». 
der esta explicación agustiniana del sacramentum hay que tener en cuenta que el santo parte del dato de fe cuyo significado para el fiel quiere hacer entender. Ahora bien, esa inteligencia va unida a los signos del pan y vino (sacramentos) bajo los que se oculta el cuerpo y sangre del Señor. El cuerpo y sangre de Cristo le lleva al signo que los oculta, pero que no es signo de ellos, sino del efecto que produce.

En efecto, las palabras del predicador dejan clara la identificación del entender (aliud intellegitur) con el fruto espiritual (fructum... spiritualem). Esta circunstancia invita a ser cautos: cuando san Agustín habla de entender el sacramento, no se refiere al hecho de la presencia real, sino a su efecto en quien lo recibe. En su lenguaje, entender la Eucaristía no significa descifrar el modo como el pan y el vino se convierten en el cuerpo y sangre de Jesucristo, sino llegar al fruto que produce en los comulgantes. El entender implica siempre dar un paso más. Por no advertirlo debidamente, algunos autores tropezaron en muchas de las afirmaciones agustinianas y sacaron conclusiones indebidas. Es el caso de cuantos, al no distinguir numéricamente el segundo paso del tercero, creyendo que el tercero era sólo la explicación del segundo, encontraron dificultad en colocar al obispo de Hipona entre los realistas, ubicándole entre los simbolistas. En efecto, como veremos, es el tercer paso el que goza de modo absoluto de las preferencias del teólogo y catequista Agustín.

En la continuación del sermón, el predicador, invirtiendo el orden en que los mencionó antes -la figura retórica del quiasmo-, se ocupa, primero, del intellegitur o fructus spiritualis y, luego, del uidetur o species corporalis.

1) El intellegere o fructus spiritualis lo concreta el catequista en estos términos: «Si quieres entender (intellegere) de qué cuerpo de Cristo se trata, escucha al Apóstol que dice a los fieles: 'Vosotros sois el cuerpo de Cristo; vosotros sois sus miembros' (1 Cor 12,27)»15. El objeto del entender no es otra cosa que el fruto espiritual -es decir, obra del Espíritu-: la condición de cuerpo de Cristo, en cuanto miembros suyos, de los comulgantes: «Por tanto, si vosotros sois el cuerpo de Cristo y sus miembros, sobre la mesa del Señor está puesto el misterio que sois vosotros: recibís el misterio que sois vosotros. A eso que sois, respondéis "Amén", y al responder (así) lo rubricáis. Escuchas, pues: “cuerpo de Cristo”, y respondes:

15. S. 272: «Corpus ergo Christi si uis intellegere, apostolum audi dicentem fidelibus, uos autem estis corpus Christi, et membra (1 Cor 12,27)». 
"Amén". Sé verdadero miembro del cuerpo de Cristo, para que tu "Amén" responda a la verdad»16.

2) El uidere o species corporalis está al servicio del intellegere. Si expone brevemente el proceso de la elaboración del pan y del vino que se ven sobre el altar, es para mostrar cómo en él está significado ya el fruto de la unidad ${ }^{17}$.

De lo dicho se comprende que no estamos ante realidades independientes entre sí, sino íntimamente interrelacionadas: el intellegitur se entiende desde el uidetur, lo que se entiende está ya apuntado en lo que se ve, o, al revés, el uidetur está orientado al intellegitur: lo que se ve apunta ya a lo que se entiende. Pero no es lo primero -lo que se ve- lo que produce lo tercero -lo que se entiende-; lo que lo produce es lo segundo -lo que se cree-; lo primero se limita a apuntarlo.

b) Sermón 22718. Este sermón es, como el 272, una pieza de catequesis dirigida a los que acababan de recibir su primera comunión la noche anterior, después de ser bautizados durante la celebración de la Vigilia Pascual. En sí mismo es una pieza maestra que contiene, de forma sintética, prácticamente todos los aspectos de la teología eucarística agustiniana. El sermón consta de dos partes que podemos denominar, respectivamente, sacramental y ritual. Aun reconociendo que la segunda es rica en con-

16. S. 272: «Si ergo uos estis corpus Christi et membra, mysterium uestrum in mensa dominica positum est: mysterium uestrum accipitis. Ad id quod estis, amen respondetis, et respondendo subscribitis. Audis enim, corpus Christi; et respondes, amen. Esto membrum corporis Christi, ut uerum sit amen».

17. S. 272: «Quare ergo in pane? Nihil hic de nostro afferamus, ipsum apostolum identidem audiamus, qui cum de isto sacramento loqueretur, ait, unus panis, unum corpus multi sumus (1 Cor 10,17): intellegite et gaudete; unitas, ueritas, pietas, caritas. Unus panis (1 Cor 10,17): quis est iste unus panis? Unum corpus multi (1 Cor 10,17). Recolite quia panis non fit de uno grano, sed de multis. Quando exorcizabamini, quasi molebamini. Quando baptizati estis, quasi conspersi estis. Quando spiritus sancti ignem accepistis, quasi cocti estis. Estote quod uidetis, et accipite quod estis. Hoc apostolus de pane dixit. Iam de calice quid intellegeremus, etiam non dictum, satis ostendit. Sicut enim ut sit species uisibilis panis, multa grana in unum consperguntur, tanquam illud fiat, quod de fidelibus ait scriptura sancta, erat illis anima una, et cor unum in deum (Act 4,32): sic et de uino. Fratres, recolite unde fit uinum. Grana multa pendent ad botrum, sed liquor granorum in unitate confunditur. Ita et dominus Christus nos significauit. Nos ad se pertinere uoluit, mysterium pacis et unitatis nostrae in sua mensa consecrauit. Qui accipit mysterium unitatis, et non tenet uinculum pacis, non mysterium accipit pro se, sed testimonium contra se».

18. Todos los autores coinciden en que fue predicado en Hipona en la mañana de Pascua, pero discrepan en cuanto al año: 414 ó 415 (E. Hill y J. Anoz); 416-417 (A. Kunzelmann). 
tenido doctrinal, sólo nos interesa la primera en la que encontramos el iter ya señalado.

Una presentación programática tiene este tenor literal: «A vosotros que acabáis de ser bautizados os había prometido explicaros en la homilía el sacramento de la mesa del Señor (cf. 1 Cor 10,21), que también ahora estáis viendo y del que participasteis la noche pasada. Debéis conocer qué habéis recibido, qué vais a recibir y qué debéis recibir a diario»19. Está claro que no es idéntica a la del s. 272 y que no se distingue por la nitidez sino por la ambigüedad. A primera vista sólo contempla dos pasos: el ver -«que también ahora estáis viendo»- y el conocer -«conocer qué habéis recibido, qué vais a recibir y qué debéis recibir a diario»-. Pero en la práctica ese conocer incluye el paso segundo y el tercero, como lo deja ver la continuación del sermón que contiene inequívocamente los tres.

El primer paso está contenido en estas palabras: «El pan que estáis viendo sobre el altar»; el segundo, en estas otras: «santificado por la palabra de Dios, es el cuerpo de Cristo. El cáliz o, más exactamente, lo que contiene el cáliz, santificado por la palabra de Dios, es la sangre de Cristo (cf. Mt 26,26-28). Mediante estos elementos quiso Cristo, el Señor, confiarnos su cuerpo y su sangre que derramó por nosotros para la remisión de los pecados (cf. Mt. 26,28)». El tercero, por último, en estas: «Si lo habéis recibido santamente, vosotros sois lo que habéis recibido. Pues dice el Apóstol: Siendo muchos, somos un único cuerpo, un único pan (1 Cor 10,17). Es la manera como él expuso el sacramento de la mesa del Señor: Siendo muchos, somos un único cuerpo, un único pan»20.

El primer paso es corto: una simple referencia al pan que están viendo sobre el altar; el segundo, esta vez algo más largo, afirma lo que es -el pan es el cuerpo de Cristo, el vino es la sangre de Cristo-; el tercero, siempre breve, expresa lo que han de conocer, esto es, el fruto que produce -sois lo que habéis recibido-, con el apoyo bíblico habitual en san Agustín (1 Cor 10,17). Pero no hay que olvidar la condición que pone: «Si lo habéis recibido santamente», donde el «lo» incluye el cuerpo y la sangre del

19. S. 227: «Promiseram enim uobis, qui baptizati estis, sermonem quo exponerem mensae dominicae sacramentum quod modo etiam uidetis et cuius nocte praeterita participes facti estis. Debetis scire quid accepistis, quid accepturi estis, quid cottidie accipere debeatis».

20. S. 227: «Panis ille quem uidetis in altari sanctificatus per uerbum dei, corpus est Christi. Calix ille, immo quod habet calix, sanctificatum per uerbum dei, sanguis est Christi. Per ista uoluit dominus Christus conmendare corpus et sanguinem suum quem pro nobis fudit in remissionem peccatorum. Si bene accepistis, uos estis quod accepistis. Apostolus enim dicit: unus panis, unum corpus multi sumus (1 Cor 10,17). Sic exposuit sacramentum mensae dominicae: unus panis, unum corpus multi sumus (1 Cor 10,17)». 
Señor. El predicador usa el verbo «recibir» dos veces: los fieles reciben el cuerpo y sangre de Cristo -segundo paso-, y reciben lo que ellos son -cuerpo de Cristo- -tercer paso-.

A continuación explica este tercer paso con la ayuda del primero, que lo significa: los fieles se constituyen en cuerpo de Cristo mediante un proceso similar al seguido por los múltiples granos para convertirse en un único pan ${ }^{21}$.

c) Sermón 229 (=Denis 6). El sermón fue predicado en la misma circunstancia que los dos anteriores ${ }^{22}$. En él, el predicador entra de lleno en el tema sin declaraciones previas. En su primera parte, se atiene al guión que hemos visto en los otros y sigue los mismos tres pasos. El primero -lo que se ve-: «esto que estáis viendo sobre la mesa del Señor es pan y vino». El segundo -lo que es-: «Pero este pan y este vino se convierten en el cuerpo y la sangre de la Palabra al llegarles la palabra». Segundo paso que se prolonga con reflexiones sobre la encarnación de la Palabra, que encuentra su justificación en la misericordia divina. El tercero -lo que significa-: «nos confió en este sacramento su cuerpo y sangre, en que nos transformó también a nosotros mismos» 23 .

A continuación, una vez más, explica este tercer paso con la ayuda del primero que lo significa: los fieles se constituyen en cuerpo de Cristo mediante un proceso similar al seguido por los múltiples granos para convertirse en un único pan ${ }^{24}$.

21. S. 227: «Conmendatur uobis in isto pane quomodo unitatem amare debeatis. Numquid enim panis ille de uno grano factus est? Nonne multa erant tritici grana? Sed antequam ad panem uenirent separata erant; per aquam coniuncta sunt post quamdam contritionem... Sic et uos ante ieiunii humiliatione et exorcismi sacramento quasi molebamini. Accessit baptismum et aqua quasi conspersi estis ut ad formam panis ueniretis. Sed nondum est panis sine igne. Quid ergo significat ignis, hoc est chrisma olei? Etenim ignis nutritor spiritus sancti est sacramentum...».

22. No todos los autores admiten la autenticidad agustiniana de este sermón. Entre los que la admiten todos los fechan entre el 405 y el 411.

23. S. 229 (=Denis 6), 1: «Hoc quod videtis, carissimi, in mensa domini, panis est et vinum: sed iste panis et hoc vinum accedente verbo fit corpus et sanguis Verbi. Ille enim Dominus, qui in principio erat Verbum (Io 1,1), et Verbum erat apud Deum, et Deus erat Verbum, propter misericordiam suma, qua non contempsit quod creavit ad imaginem suam, Verbum caro factum est, et habitavit in nobis (Io 1,14), sicut scitis; quia et ipsum Verbum adsumpsit hominem, id est, animam et carnem hominis, et homo factus est, manens deus. Propter hoc, quia et passus est pro nobis, commendavit nobis in isto sacramento corpus et sanguinem suum, quod etiam fecit et nos ipsos. Nam et nos corpus ipsius facti sumus, et per misericordiam ipsius, quod accipimus, nos sumus».

24. S. 229 (=Denis 6),1: «Recordamini quid fuit aliquando creatura ista in agro, quomodo eam terra peperit...; deinde labor humanus... Recordamini et vos: non fuistis et crea- 
d) Sermón 229 A (=Guelf 7)25. En esta nueva catequesis eucarística el predicador mantiene los mismos pasos, pero no de forma tan linear. Tras un párrafo previo, llega a la afirmación: «Lo que estáis viendo sobre la mesa del Señor, por lo que se refiere a su aspecto exterior, estáis acostumbrados a verlo también en las vuestras; el aspecto exterior es el mismo, pero distinto el efecto que produce» ${ }^{26}$. En esta frase se hace referencia al primer y al tercer paso. Al primero -lo que se ve-, en estas palabras: «Lo que estáis viendo sobre la mesa del Señor, por lo que se refiere a su aspecto exterior, estáis acostumbrados a verlo también en las vuestras»; al tercero -lo que produce-, en estas otras: «el aspecto exterior es el mismo, pero distinto el efecto que produce». De momento no indica lo que produce, pero sí que produce algo. Lo que acontece en el bautismo le sirve como ejemplo de referencia ${ }^{27}$.

Inmediatamente después hace ya el recorrido de los tres pasos. El primero: «Tal como lo veis, es aún pan y vino»; el segundo: «cuando llegue la santificación (=consagración), ese pan será el cuerpo de Cristo y el vino su sangre»; el tercero: «El nombre y la gracia de Cristo hacen que los ojos sigan percibiendo lo que percibían antes y que, sin embargo, no tenga el mismo valor que antes. Si uno lo comía antes, le saciaba el vientre; si lo come ahora, le edifica el espíritu»28. Tampoco aquí nos ha dicho de qué sé trata; se limita a indicar la existencia de un nuevo valor, de una realidad que edifica el espíritu, pero sin especificar. Lo hará un poco más adelante, sirviéndose de las dos citas paulinas habituales en el predicador en este contexto, 1 Cor 10,17 y 12,27: el cuerpo eclesial de Cristo ${ }^{29}$. También en

ti estis... postea ad aquam venistis, et consparsi estis, et unum facti estis. Accedente fervore Spiritus sancti cocti estis, et panis dominicus facti estis. ... Sic et vinum in multis acinis fuit, et modo in unum est... Et vos post illa ieiunia... ad calicem domini venistis...».

25. Los autores lo fechan entre el 410 y el 412.

26. S. 229 (= Guelf. 7), 1: «Quod uidetis in mensa domini, quantum pertinet ad ipsarum rerum speciem, et in uestris mensis uidere consuestis: ipse est uisus, sed non ipsa uirtus».

27. S. 229 (=Guelf 7), 1: «Nam et uos idem ipsi estis homines, qui eratis: neque enim ad nos nouas facies attulistis. Et tamen noui estis: ueteres corporis specie, noui gratia sanctitatis, sicut et hoc nouum est».

28. S. 229 (= Guelf 7), 1: «Adhuc quidem, quomodo uidetis, panis est et uinum: accedit sanctificatio, et panis ille erit corpus Christi, et uinum illud erit sanguis Christi. Hoc facit nomen Christi, hoc facit gratia Christi, ut hoc ipsum uideatur quod uidebatur, et tamen non hoc ualeat quod ualebat. Antea enim si manducaretur, inpleret uentrem; modo cum manducatur, aedificat mentem».

29. S. 229 (= Guelf. 7), 1: «Ita et modo non ex corde nostro, neque ex praesumtione nostra, neque ex humanis argumentationibus, sed ex auctoritate apostoli, opus est uobis commendare et insinuare, quid sit quod accepistis uel accepturi estis. Ecce breuiter audite apostolum, immo Christum per apostolum, de sacramento mensae dominicae quod ait: 
este sermón explica, más adelante, este tercer paso sirviéndose, como ya en los anteriores y de la misma manera, del primero. En el presente, sin embargo, pone énfasis en que el cuerpo de Cristo se construye mediante la concordia de la unidad ${ }^{30}$.

Después del análisis, la síntesis. Los cuatro sermones que hemos examinado siguen los tres pasos indicados y en el mismo orden. El primero: la referencia al pan y al vino presentes (o vistos) sobre el altar; el segundo: la referencia al cuerpo y sangre de Cristo (de la Palabra) que son -o en que se convierten- el pan y el vino por obra de la palabra; el tercero: la referencia a la realidad del cuerpo de Cristo que reciben y son los que participan del altar. El interés del predicador se centra en que sus oyentes conozcan, sobre todo, el paso tercero por lo que, en consecuencia, obtiene un más amplio desarrollo. En los cuatro sermones el obispo catequista explica el tercer paso recurriendo al primero del que toma la similitud. Aunque siempre se refiere a la misma realidad, el tercer paso aparece contemplado desde distintas perspectivas: como realidad cognoscible (algo que hay que entender [intellegere], algo que hay que conocer [scire quid accepistis]), como realidad evaluable (algo que tiene un valor específico [non hoc ualeat quod ualebat]), como efecto producido (edifica la mente [aedificat mentem]), como fruto espiritual, como potencialidad (virtus).

Es importante el hecho de que los textos estudiados sean catequéticos, no exegéticos, polémicos o teológicos. Cuando el obispo actúa como teólogo, puede estar interesado únicamente en aclarar un punto concreto de la fe eucarística de la Iglesia; cuando actúa como polemista puede estar

unus panis, unum corpus multi sumus (1 Cor 10,17). Ecce totum est, cito dixi: sed appendite uerba, nolite numerare. Si uerba numeratis, breue est; si appenditis, grande est. Vnus panis, dixit. Quotquot ibi panes positi fuerint, unus panis: quotquot panes fuerint in altaribus Christi hodie per totum orbem terrarum, unus panis est. Sed quid est, unus panis? Exposuit breuissime: unum corpus multi sumus (1 Cor 10,17). Hoc panis corpus Christi, de quo dicit apostolus, alloquens ecclesiam: Vos autem estis corpus Christi et membra (1 Cor 12,27). Quod accipitis, uos estis, gratia qua redempti estis; subscribitis, quando amen respondetis. Hoc quod uidetis, sacramentum est unitatis».

30. S. 229 (= Guelf 7) 2: «Iam quia breuiter nobis insinuauit apostolus quid hoc esset, considerate illud diligentius et uidete, quomodo fiat. Quomodo fit panis? Trituratur, molitur, a consparsura, in coctura: in consparsura mundatur, coctura firmatur. ubi tritura uestra? Hoc facti estis: ipsa fuit in ieiuniis, in obseruationibus, in uigiliis, in exorcismis. Molebamini, quando exorcizabamini. Consparsura non fit sine aqua: baptizati estis... quomodo autem de singulis granis in unum congregatis et quodam modo sibimet consparsione commixtis fit unus panis, sic fit unum corpus Christi concordia caritatis. Quod autem habet corpus Christi in granis, hoc sanguis in acinis: nam et uinum de pressura exit, et quod in multis singillatim erat, in unum confluit, et fit uinum. Ergo et in pane et in calice mysterium est unitatis». 
empeñado en poner de relieve determinado aspecto de ella; cuando actúa como exégeta, lógicamente está condicionado por el texto que comenta; en cambio, cuando actúa como catequista, y específicamente como catequista en la etapa de la iniciación cristiana, lo único que le limita es la fe de la Iglesia, pues en la medida en que es un pastor responsable, y san Agustín lo era a buen seguro, ha de esforzarse en exponérsela de la forma más completa y precisa posible a los recién bautizados. Por tanto, cuando se trata de conocer lo que san Agustín pensaba globalmente sobre la Eucaristía es a estos sermones a los hay que recurrir en primera instancia. Comparados con otros textos que contienen también doctrina eucarística, estos ofrecen tres grandes ventajas: la primera que en ellos el santo no está condicionado por la disciplina del arcano, puesto que todos sus oyentes estaban bautizados; la segunda, que presentan la fe completa de la Iglesia, tal como la poseía el catequista; la tercera, que aportan claves para interpretar otros pasajes de sus obras. Un sano juicio reclama, pues, asignar a estos sermones su justo valor criteriológico, distinguiéndolos de los demás textos.

Ahora bien, aunque el catequista trate de trasmitir con toda fidelidad la fe de la Iglesia, en este caso sobre la Eucaristía, ésta llevará inevitablemente su marca personal. Siempre será su visión personal de la fe de la Iglesia, condicionada por su modo de ser, por su propio mundo de ideas, por la situación misma de la Iglesia. Y esa visión personal tendrá sus repercusiones particulares, tanto en el método como en el contenido. En el caso de Agustín, por lo que se refiere al contenido, salta a la vista la vinculación profunda que establece entre Eucaristía y unidad. Este aspecto de la doctrina agustiniana tiene como sólida base bíblica dos textos paulinos: 1 Cor 10,17 y 12,27. Pero detrás de la preferencia otorgada a estos textos sobre otros, como pueden ser los relatos de la institución (cf. Mt 26,2629; Mc 14,22-25; Lc 22,15-20; 1 Cor 11,23-25) o el discurso del pan de vida (cf. Jn 6, 27-71) ${ }^{31}$, está, sin duda, la tradición patrística anterior a él, pero también su propia formación neoplatónica que le impulsaba hacia la unidad y, sobre todo, el hecho de ejercer su ministerio al servicio de una Iglesia que sufría en sus carnes el cisma. Por lo que se refiere al método, surge la pregunta: ¿Qué explicación cabe dar de los tres pasos mencionados? ¿De dónde le vino al catequista Agustín el proceder de esa precisa manera? Veámoslo.

31. Aunque comenta ampliamente en sus Io. eu. $\operatorname{Tr}$ el texto, prescinde de él en estas catequesis a los iniciados. 


\section{Tres status quaestionis de la retórica clásica}

La catequesis examinada tomaba la forma de un sermón dentro de la celebración eucarística, una vez que se habían ausentado los catecúmenos y los penitentes. Era, en definitiva, una pieza oratoria para un momento solemne, en el que el público oyente podía variar respecto del habitual no sólo en número sino también en condición social y cultural. Al reclamo de la fiesta en sí misma, se unía el hecho de los nuevos iniciados en la fe de la Iglesia. Por otra parte, el haber pasado toda la noche en vela se traducía inevitablemente en cansancio y no era, en consecuencia, el momento más adecuado para un largo discurso, aunque se considerase a tono con la circunstancia. Pero aún dentro de la brevedad y la sencillez, el orador no dejaba de hacer uso de sus antiguos conocimientos retóricos, que los entendidos reconocerían sin dificultad. Procede, pues, volver los ojos a la retórica. En ella encontremos la respuesta a los interrogantes formulados.

A propósito de las cuestiones racionales o lógicas, la retórica clásica distinguía mayoritariamente cuatro status, esto es, el estado de la cuestión o punto en que consiste la causa que va a defender el orador: status coniecturae, statis finitionis, status qualitatis y status translationis. El primero pregunta si se dio el hecho objeto de la causa, el segundo lo define con propiedad, el tercero lo valora desde el criterio adecuado y el cuarto determina la competencia de quien lo trata. Esas cuatro cuestiones aparecen reducidas, ya en Cicerón, a las tres siguientes: an sit (si existe), quid sit (qué es) y quale sit (cómo es) ${ }^{32}$. Formulan preguntas que, según Quintiliano ${ }^{33}$, vienen dadas por la misma naturaleza y tienen validez universal, esto es, para todo tipo de causa y tanto para las cuestiones de naturaleza general (infinitae) como las de naturaleza concreta (finitae) ${ }^{34}$.

La misma retórica clásica, ya desde Aristóteles, consideraba los distintos ámbitos concretos en que hallaban aplicación esos status. Los designaba como genera y enumeraba tres: el iudiciale, el deliberativum y el demonstrativum. El iudiciale tiene su ámbito propio ante un tribunal que juzga hechos del pasado; el deliberativum, ante una asamblea a la que se invita a tomar una decisión de futuro; el demonstrativum, ante un grupo de personas ante el que se pronuncia un elogio de alguien o de algo ${ }^{35}$. De los tres genera, ni el iudiciale ni el demonstrativum son asimilables a nues-

32. Cf. De oratore $2,26,113$.

33. Institutio oratoria 3,6,80-81.

34. Cf. H. LAUSBERG, Manual de retórica literaria, Madrid 1966, t. I, nº 134.

35. Cf. H. LAUSBERG, Manual de retórica literaria, Madrid 1966, t. I, nº . 59-65. 
tros sermones; sí, en cambio, el deliberativum. Por la razón que luego indicaremos, nos interesa el tercero de los status, el status qualitatis o la pregunta quale sit. Si en el genus iudiciale, el criterio según el cual se valora lo que está en causa era la ley (an iure fecerit), y en el demonstrativum, la honestidad (an honestum/turpe sit), en el deliberativum el criterio es la utilidad (an respectu utilitatis faciendum) ${ }^{36}$.

En su predicación el obispo de Hipona nunca menciona el conjunto de los distintos status quaestionis, pero lo hace en otros escritos. La Carta 11 es un testimonio palmario de cómo el santo recurre a ellos para resolver una cuestión doctrinal, esto es, racional. Partiendo de la enseñanza católica de que todas las obras de la Trinidad son comunes al Padre, al Hijo y al Espíritu Santo, Nebridio había preguntado a su amigo Agustín por qué, entonces, la encarnación se asignaba solamente al Hijo. Para darle respuesta, que, por cierto, se apartaba de la fe católica pues sostiene la encarnación de las tres divinas personas, Agustín argumenta a partir de los tres status. Al amigo le hace saber que no hay ninguna sustancia que no tenga estas tres cosas: en primer lugar que exista (ut sit), luego que sea una cosa u otra (ut hoc uel illud sit), y en tercer lugar que permanezca en cuanto pueda en lo que es (ut in eo ipso quod est maneat) ${ }^{37}$. Después de hacer la aplicación a la doctrina trinitaria, prosigue: «Si ves que lo que es necesariamente tiene que ser eso o lo otro y mantenerse en su género todo lo posible, nada hacen las tres Personas separadamente»38. A partir de ese esquema retórico el santo cree haber probado con cuánta verdad se entiende en la Católica la inseparabilidad de la Trinidad ${ }^{39}$. Más adelante vuelve sobre la misma idea: «En aquellas tres clases de cuestiones, aunque se pregunte por su existencia (an sit), se incluye también el qué es (quid sit), pues no podría existir si no fuese algo; y también hay que ver si se ha de aprobar o reprobar (probandum inprobandumne sit), pues todo lo que existe es digno de alguna estimación. Por ende, cuando se pregunta qué es, es necesario que exista y merezca alguna estimación. Del mismo modo, cuando se pregunta por la cualidad, es ya algo, sin duda. Y pues los tres

36. Cf. H. Lausberg, Manual de retórica literaria, Madrid 1966, t. I, nº 171-196; 252$253 ; 237$.

37. Ep. 11,3: «Nulla natura est, Nebridi, et omnino nulla substantia, quae non in se habeat haec tria et prae se gerat: primo ut sit, deinde ut hoc uel illud sit, tertio ut in eo ipso, quod est, maneat, quantum potest».

38. Ib.: «At si cernis necesse esse ut, quicquid sit, continuo et hoc uel illud sit et in suo genere maneat, quantum potest, nihil tria illa praeter inuicem faciunt».

39. $I b .:$ "sed breuiter tibi aperire uolui, si tamen egi, quod uolui, quam subtiliter et quanta ueritate in catholica intellegatur huiusce inseparabilitas trinitatis». 
elementos son inseparables, la cuestión no toma nombre de todos, sino (de uno de ellos) según la intención del que plantea la cuestión» ${ }^{40}$. Luego infiere dos consecuencias referidas al tema que tiene entre manos. Una: «Era, pues, necesaria para los hombres la disciplina en que fueran iniciados y por la que fueran ordenadamente formados. ¿Acaso diremos que lo que se realiza en los hombres por la disciplina no existe o no es apetecible? Mas, ante todo, buscamos conocer un medio por el que deduzcamos que existe algo y en lo que nos mantengamos» 41 . Otra: «Era, pues, necesario mostrar primero una cierta norma y regla de disciplina. Y eso se verificó por ese plan de la asunción del hombre, que hemos de atribuir propiamente al Hijo; así sería consiguiente, por medio del Hijo, el conocimiento del mismo Padre, esto, es del único principio de quien proceden todas las cosas, y también una cierta interior e inefable suavidad y dulzura para permanecer en ese conocimiento y desdeñar todo lo mortal, don y función que se atribuye propiamente al Espíritu Santo»42. Y, por último: «Aunque todo tenga lugar en completa unión e inseparabilidad, había que señalar una distinción, por nuestra debilidad, pues hemos caído de la unidad en la diversidad» 43 .

Este recurso al esquema retórico por parte de Agustín no tiene nada de extraño, habida cuenta de que la carta la escribió no mucho después de abandonar la docencia de la retórica, aunque no se le pueda asignar fecha exacta. Más significativo es, sin embargo, que, casi tres lustros después de desertar de su antigua profesión, el santo confiese que sigue utilizando a menudo ese mismo esquema. Efectivamente, en un pasaje del libro déci-

40. Ep. 11,4: « ... uelut in illis tribus generibus quaestionum, etiam si quaeratur, an sit, ibi est et quid sit, esse enim non potest profecto, nisi aliquid sit; ibi etiam, probandum inprobandumne sit, quicquid enim est, nonnulla aestimatione dignum est; ita cum quaeritur, quid sit, necesse est, ut et sit et aliqua aestimatione pendatur; hoc modo etiam cum quaeritur, quale sit, et aliquid est utique. ita cum sibi inseparabiliter iuncta sunt omnia, nomen tamen quaestio non ex omnibus accipit, sed ut sese habuerit quaerentis intentio».

41. Ep. 11, 4: «... ergo disciplina hominibus erat necessaria, qua inbuerentur et qua ad modum formarentur. Num tamen id ipsum, quod per hanc disciplinam fit in hominibus, aut non esse possumus dicere aut non appetendum? Sed scire prius intendimus, et per quod coniciamus aliquid et in quo maneamus».

42. $E p$ 11,4: «Demonstranda igitur prius erat quaedam norma et regula disciplinae. Quod factum est per illam suscepti hominis dispensationem, quae proprie filio tribuenda est, ut esset consequens et ipsius patris, id est unius principii, ex quo sunt omnia, cognitio per filium et quaedam interior et ineffabilis suauitas atque dulcedo in ista cognitione permanendi contemnendique omnia mortalia, quod donum et munus proprie spiritui sancto tribuitur».

43. Ep. 11,4: «Ergo cum agantur omnia summa communione et inseparabilitate, tamen distincte demonstranda erant propter inbecillitatem nostram, qui ab unitate in uarietatem lapsi sumus». 
mo de las Confesiones enumera los tres status, sin dar más explicaciones: «Cuando oigo que sobre cualquier cosa se pueden plantear tres cuestiones, a saber, sobre su existencia (an sit), sobre su esencia (quid sit) y sobre su cualidad (quale sit)...»44. Pero, un poco más adelante, dentro de la síntesis que está presentando de todo el recorrido hecho hasta entonces, añade algo más. Este es el texto: «Ni yo mismo -digo- cuando hacía esto, o más bien, la facultad mía con que lo hacía, ni aun esta misma eras tú, porque tú eras la luz indeficiente a la que yo consultaba sobre todas las cosas: si existían (an essent), qué eran (quid essent) y cuánto valían (quanti pendenda essent) ${ }^{45}$. Dejando de lado el modo diferente de designar ahora el tercer status, lo más significativo es la afirmación de consultaba a Dios respecto de cualquier cosa si esta existía, qué era y cuál era su valor. Esto es, estamos ante un esquema retórico del que el santo aún hacía pleno y constante uso cuando escribía el libro décimo de las Confesiones. Y nada impide pensar que no siguiera haciéndolo después.

Estos textos -sobre todo el primero- son ricos en datos aprovechables para nuestro propósito. Testimonian, antes que nada, que san Agustín conocía esta clasificación ternaria, dada por Cicerón, de los status quaestionis. Testimonian, además, que el santo recurre a ella para solventar cuestiones teológicas. Por otra parte, advertimos diversas formas de referirse a cada uno de los status, diversidad que es notablemente mayor para el tercero. El primer status aparece indicado en los siguientes términos: an sit/essent, coniicere, principium; el segundo en estos: quid sit/essent, hoc vel illud sit; non esse, scire, cognitio; el tercero en estos otros: quale sit, quanti pendenda essent, quod maneat; probandum improbandum sit; aliqua aestimatione pendatur; non appetendum, manere, suavitas et dulcedo. No menos

44. Conf. 10,10,17: «At uero, cum audio tria genera esse quaestionum, an sit, quid sit, quale sit...».

45. Conf. 10,40,65: «Nec ego ipse, cum haec agerem, id est uis mea, qua id agebam, nec ipsa eras tu, quia lux es tu permanens, quam de omnibus consulebam, an essent, quid essent, quanti pendenda essent....».

No tres, sino cuatro status son mencionados en la obra De Rethorica 9-10, de atribución dudosa al santo: «... igitur rationales seu logicae quaestiones fiunt modis quattuor; haec enim in illis quaeruntur: an sit, quid sit, quale sit, an induci in iudicium debeat. Vbi quaeritur an sit, genus id quaestionis Hermagoras "stochasmón" uocat, nos coniecturam possumus dicere: idem Theodorus "perì tes ousias", id est de substantia. Nihil enim neque factum uideri potest, quod non habuerit substantiam, neque futurum, quod non habiturum sit substantiam. Quidam hoc genus quaestionis ex co, quod per id quaeritur, an sit uocauerunt. Altera rationalis est quaestio, quam Hermagoras finem uocat, Theodorus "perì tes idiotetos", id est de proprietate, quidam quid sit, nonulli de eodem et altero, id est"perì tou autou kaì perì tou thaterou". Tertiam rationallem quaestionem uno nomine omnes qualitatem uocant. 10. De quarta magna contentio est, quam supra de inducendo iudicio diximus». 
importantes consideramos otras dos constataciones agustinianas: la primera, que los tres status se implican los unos a los otros, por lo que, aunque sólo se afirme explícitamente uno, implícitamente quedan afirmados los otros dos; la segunda, que, aunque se den en plena comunión, es preciso distinguirlos.

\section{De los « status» a los «pasos»}

La aplicación de los status a nuestro tema se puede concretar en los siguientes puntos:

1) En su cátedra de Hipona, san Agustín no se presenta como orador sino como doctor cristiano. Eso explica que no manifieste interés alguno en hacer uso de la terminología técnica que le procuraba la retórica que en su momento había enseñado. Lo cual no obsta para que él hiciese uso, incluso conscientemente, de lo aprendido en su antigua profesión.

2) De hecho, los tres pasos de la catequesis agustiniana parecen corresponder a los tres status quaestionis. a) Cuando el catequista hace relación al pan y al vino que están sobre el altar, implícitamente ha respondido a la cuestión an sit. b) Cuando el catequista señala que el pan y el vino son respectivamente el cuerpo y la sangre del Señor, ha respondido implícita pero claramente a la cuestión quid sit. c) Cuando el catequista indica qué reciben los que comulgan, todo apunta a que está respondiendo a la cuestión quale sit. En efecto, a) la constatación de que los neófitos mismos están viendo sobre el altar el pan y el vino es una constatación de «existencia»; b) la afirmación de que el pan y el vino son, respectivamente, el cuerpo y la sangre del Señor, es una afirmación de «esencia»-en el caso concreto, la afirmación de la presencia real-; c) la afirmación de que los comulgantes reciben lo que son o son lo que reciben, esto es, el cuerpo de Cristo, es una afirmación de «cualidad» y de valor; más aún, de gran valor.

3) Admitido que, detrás de los pasos del catequista Agustín, se ocultan los status, si estos son numéricamente distintos, también hay que considerar como numéricamente distintos a aquellos. Y esto es lo que parece que no han percibido algunos intérpretes de la doctrina eucarística agustiniana. Al no distinguir el segundo del tercero, era de todo punto necesario que tacharan la doctrina del obispo de Hipona de ambigua e incoherente. Si las cuestiones quid sit y quale sit conllevan respuestas diferentes, cuando se juzga que en todos los casos se responde a la única cuestión del 
quid sit, resulta inevitable percibir ambigüedad en sus textos y más que probable detectar incoherencias.

4) Si los tres status se implican mutuamente, los tres pasos del catequista están también mutuamente implicados. En consecuencia, aunque el predicador se refiera a uno solo, hay que pensar que cuenta con los tres. Como bastantes veces san Agustín se ocupa sólo del tercer paso, algunos intérpretes, entendiendo su enseñanza como si perteneciese al segundo, han cuestionado, cuando no negado abiertamente, que el santo sostuviese la presencia real de Cristo en la Eucaristía. El santo no hace más que hablar del fruto espiritual -por emplear la expresión del sermón 272- del sacramento; pero si hay fruto del sacramento es porque hay sacramento $y$ hay sacramento porque previamente hay pan y vino. Acomodando a nuestro caso lo que el santo escribía en la Carta 11 a propósito del considerado entonces, como los pasos son inseparables, no es preciso mencionar expresamente cada uno de ellos; basta con que el predicador, según los intereses del momento, se ocupe de uno. Es lo que hace el santo en otros textos eucarísticos.

5) En los cuatro sermones que hemos examinado el santo ha dado los tres pasos, pero en todos ellos -insistimos- su interés se ha centrado en el tercero, que se corresponde con la cuestión quale sit. Como indicamos, según la retórica clásica el criterio conforme al cual se juzgaba la qualitas en el genus deliberativum era la utilidad (utilitas). Pero los textos en que san Agustín argumenta sobre la base de los tres géneros de cuestiones, o simplemente los menciona, están desvinculados de un contexto de enseñanza de la retórica. Por ello, junto a las fórmulas tradicionales, encontramos otras formas de expresión de la misma realidad, suscitadas por el tema al que aplica el esquema retórico. En concreto, la utilitas clásica adquiere en los textos del santo examinados la forma de lo valioso (quanti pendenda; aliqua aestimatione pendenda), de lo aprobado (probandum improbandum sit), de lo permanente (quod maneat, manere), de lo apetecible (non appetendum), del sabor agradable y de la dulzura (suauitas et dulcedo). Y si volvemos los ojos a los sermones catequéticos, esa utilitas toma la forma de valor (non hoc ualeat quod ualebat), de don recibido (quid accepistis), de efecto producido (aedificat mentem), de fruto (fructum spiritualem), de potencialidad (virtus). El cuerpo de Cristo tiene la qualitas de integrar en sí mismo a todos los que lo reciben, algo que evidentemente resulta de suma utilidad para el receptor. Su utilitas está en su uirtus, en esa capacidad integradora. Es evidente que, por grande que sea el valor del pan y del vino para el hombre, es para él un valor infinita- 
mente mayor el estar integrado en el cuerpo de Cristo; tiene el valor de ser fruto, don del Espíritu, para el espíritu. Tampoco hay comparación entre llenar el vientre y edificar el espíritu. Así, pues, no cabe algo más útil. Por eso es una qualitas que justifica la celebración y participación en el sacramento. Pero, a la vez, se trata de una qualitas que excede la pura percepción visual. De ahí la afirmación del predicador de que los neófitos necesitan una inteligencia que sólo les puede llegar desde la fe: 'Si no creéis, no entenderéis (Is 7,9 [LXX])'. Si no hay fe, no hay inteligencia. No puede producirse la integración en el cuerpo de Cristo -he aquí la concreción de la «cualidad»-sino hay cuerpo de Cristo -he aquí la «esencia»-. Pero hay que estar atentos porque no estamos ante la intellegentia de la «esencia», sino ante la intellegentia de la «cualidad» de esa «esencia»: su utilidad, esto es, su valor para quien lo recibe.

6) De toda la terminología que se hizo clásica en la teología eucarística posterior, en los sermones examinados Agustín utiliza dos términos: sacramento (sacramentum) -nueve veces, referido a la Eucaristía- y realidad (res), una sola vez. En dos sermones el predicador designa a la Eucaristía como «sacramento de la mesa del Señor» ${ }^{46}$. Más que un valor abstracto, como cuando nosotros decimos «sacramento de la Eucaristía», el término tiene un valor concreto: el sacramento es lo que está sobre la mesa del Señor. Por eso -siempre en referencia a la Eucaristía- puede hablar en plural: sacramentos. Lo hace porque para él son sacramentos tanto el pan como el vino. Pero esos elementos se convierten en sacramentos sólo a partir del momento en que son consagrados. En efecto, si todo sacramento lo es, como dice el mismo san Agustín en el sermón 272, porque en él es una cosa la que se ve y otra la que se entiende, sólo entonces pueden serlo, porque sólo a partir de entonces hay realidad (res) inteligible.

7) Ahora procede señalar cuál es esa realidad del sacramento (res sacramenti) en nuestro caso concreto. Pensando en los tres pasos señalados, los textos no dejan duda de que la realidad (res) hay que colocarla en el tercero de ellos. Con otras palabras, la realidad (res) del sacramento no responde al quid sit, sino al quale sit; es decir, no revela la «esencia», sino la «cualidad». La realidad (res) de que habla el texto no es el cuerpo y sangre del Señor ocultos en el sacramento, sino la unión al cuerpo del Señor de quienes comulgan. Con esto no se niega la presencia real, simplemente se afirma que el santo refiere la realidad (res) al efecto producido. Esto nos resulta claro por varias razones. En primer lugar, la ponderación que hace san Agustín de la gran realidad de que es sacramento lo que los pre-

46. Cf. S. 227 (2) y s. 229 A. 
sentes están viendo sobre el altar aparece como aposición explicativa del tercer paso que el predicador va a dar: los presentes están viendo sobre el altar el sacramento, pero no han oído aún qué es y qué significa, esto es, la gran realidad de que es misterio. En segundo lugar, por la definición misma de sacramento: una cosa se ve; otra se entiende (aliud uidetur, aliud intellegitur). No cabe duda de que el «se entiende» (intellegitur) se refiere a la unión con Cristo que produce la recepción del sacramento, como expusimos en su momento. Si es esencial al sacramento entender algo distinto de lo que se ve y eso que se entiende es la unidad, entonces la res esencial al sacramento es la unidad. En tercer lugar, san Agustín habla expresamente de «sacramento de la unidad» 47 , que no es otra que la unidad de los comulgantes con el cuerpo de Cristo. Para concluir, porque por tres veces recurre a 1 Cor 10,17 para explicar el sacramento, sirviéndose de la autoridad de Pablo 48 .

8) La correspondencia entre los pasos y los status pudiera no parecer, a primera vista, tan absoluta. En efecto, según la retórica, aquello cuya existencia constata el primero de los status resulta todavía indefinido y necesita, por ello, que el segundo status lo defina. Por el contrario, según nuestros sermones, aquello cuya existencia constata el primer paso, parece estar ya definido, tener ya nombre propio: pan y vino, y el segundo paso lo que haría sería definirlo de nuevo, darle un segundo nombre: cuerpo y sangre de Cristo. Pero la realidad es otra: el segundo paso propiamente no otorga un segundo nombre, sino el nombre verdadero: no se trata de pan y vino, sino del cuerpo y de la sangre del Señor. El primer paso se mueve en el uidetur $y$ el segundo en el est. Y justamente porque se trata de un $u i$ detur, de un «parecer», se requiere el segundo paso que defina el est, la realidad auténtica. Como ya indicamos, el obispo tiene en mente el pan y vino ya consagrados. La consagración no sólo transforma el pan y el vino en el cuerpo y la sangre del Señor; de hecho, también hace que el verbo videre se transforme en videri: lo que antes era visto como pan y vino, después sólo lo parecen.

9) Así, pues, la consideración de los tres pasos, puestos en relación con los tres status, nos permite una visión global de la comprensión agustiniana de la Eucaristía. En ella la presencia real ocupa el centro -el paso segundo, la respuesta al quid sit-: el cuerpo y la sangre de Cristo. Pero la pregunta sobre el quid sit se refiere a algo cuya existencia ya ha sido constatada y que «parece» pan y vino -primer paso; respuesta al an sit-. A su

47. Cf. S. $229 \mathrm{~A}, 1$

48. Cf. S. 227, 229 A,1; 272. 
vez, a lo ya definido se le reconoce una cualidad: la de unir a sí a quien lo recibe -tercer paso; respuesta al quale sit-. Cada paso está descrito por dos verbos que indican, uno, la realidad en sí misma y otro, la realidad en cuanto percibida por el fiel: videri y videre, para el primero; esse y credere, para el segundo; significari e intellegere, para el tercero. El primer paso es el de la apariencia, el segundo el de la realidad, el tercero el del significado; a su vez, el primero proviene de los sentidos, el segundo de la fe, el tercero de la inteligencia.

10) No cabe pensar en ninguna «split theory» en san Agustín. El teólogo cree exactamente lo mismo que el obispo; uno y otro proclaman la fe eucarística de la Iglesia, la fe en lo que la teología posterior denominará «presencia real». No obstante, es indiscutible que los siglos posteriores de apartaron de Agustín. Pero la diferencia no está en la fe, sino en la teología; la escolástica no asumió tal cual la teología eucarística agustiniana. Es cierta la afirmación de C. Rocchetta de que, según san Agustín, el signo (signum) remite a la realidad (res), pero no se identifica con ella; de que el signo es algo distinto de la realidad por él significada. Pero eso no afecta en absoluto a la fe en la presencia real. La doctrina del signo señalada se opone a esa presencia sólo si se la encuadra en un marco conceptual escolástico; nunca si se la encuadra en el marco conceptual agustiniano, un marco retórico como hemos visto. Cuando la única categoría con la que se trabaja es la de la «esencia» (quid sit), entonces, si el signo (signum/sacramentum) y la realidad (res) son cosas distintas, la presencia real se difumina. El signum es una cosa y la res es otra. Pero si, a la categoría de la «esencia» (quid sit) se añade la de la «cualidad» (quale sit), entonces pueden convivir perfectamente esa teoría del signo y la presencia real. El signum es una cosa y la res es otra distinta, aunque remite a ella. En este caso, el signum se identifica, sin significarla, con la «esencia», y la res con la «cualidad». El pan y el vino se convierten objetivamente en el cuerpo y sangre de Cristo (quid); pero este pan y vino, convertidos en el cuerpo y sangre de Cristo, son signo de la unidad en el cuerpo de Cristo o de la unidad del Cuerpo de Cristo (quale). El hecho de la presencia real es un dato absoluto de fe, para el que el santo no aporta explicación alguna. Pero esta presencia ha acontecido en lo que antes eran pan y vino. Y estos elementos previos, que aún parecen ser tales a los sentidos, son los que indican la realidad (res) cuya existencia la hacen posible el cuerpo y sangre de Cristo en que se han convertido. Si la qualitas es la unidad del cuerpo de Cristo, sus dos elementos se entienden bien: de la «unidad» dan razón lo que previamente eran pan y vino, que la significan, y del «cuerpo de Cristo» da 
razón el cuerpo y sangre del Señor en que se convirtieron el pan y el vino. Como nos parece cierto que la res del sacramentum eucarístico agustiniano es la unidad del cuerpo de Cristo, nos parece asimismo cierto que la afirmación en ningún modo comporta la negación o debilitamiento de la doctrina de la presencia real. Es un dato previo, condición sine qua non, para que pueda darse esta res.

11) Para concluir, digamos que en la Eucaristía se da un doble punto de partida -el pan y el vino de una parte, y los fieles, de otra- y un doble punto de llegada - el cuerpo y sangre de Cristo, de un lado, y el cuerpo eclesial de Cristo, de otro-. O, con otras palabras, se producen dos trasformaciones: el pan y el vino se convierten en el cuerpo y sangre de Cristo, y los fieles se convierten en cuerpo eclesial de Cristo. Por las dos transformaciones no son simultáneas ni se producen de la misma manera. El pan y el vino se convierten en el cuerpo y sangre de Cristo mediante la palabra santificadora o consacratoria; los fieles se convierten en cuerpo eclesial de Cristo mediante la participación en el cuerpo y sangre de Cristo. Por ello, para que se dé el cuerpo eclesial de Cristo se requiere la existencia previa del cuerpo personal de Cristo; sin la presencia de este, no cabe la existencia de aquel. El catequista Agustín afirma la primera transformación, sin explicarla; en cambio, desarrolla la segunda, tratando de hacerla comprender a los neófitos. El catequista de Hipona se comporta como pastor, no como teólogo especulativo.

Pío DE LUIS

Estudio Teológico Agustiniano Valladolid 